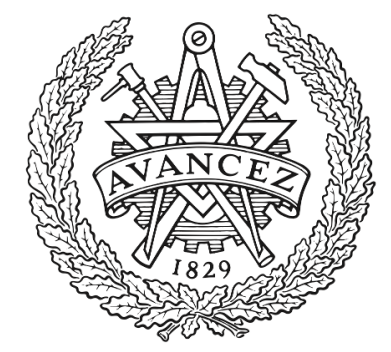

CHALMERS

UNIVERSITY OF TECHNOLOGY

\title{
Complete Reaction Cycle for Methane-to-Methanol Conversion over Cu-SSZ-13: First-Principles Calculations and Microkinetic Modeling
}

Downloaded from: https://research.chalmers.se, 2023-04-26 11:46 UTC

Citation for the original published paper (version of record):

Engedahl, U., Boje, A., Ström, H. et al (2021). Complete Reaction Cycle for Methane-to-Methanol Conversion over Cu-SSZ-13: First-Principles

Calculations and Microkinetic Modeling. Journal of Physical Chemistry C, 125(27): 14681-14688. http://dx.doi.org/10.1021/acs.jpcc.1c04062

N.B. When citing this work, cite the original published paper. 


\title{
Complete Reaction Cycle for Methane-to-Methanol Conversion over Cu-SSZ-13: First-Principles Calculations and Microkinetic Modeling
}

\author{
Unni Engedahl,* Astrid Boje, Henrik Ström, Henrik Grönbeck, and Anders Hellman*
}

Cite This: J. Phys. Chem. C 2021, 125, 14681-14688

Read Online

ABSTRACT: The steadily increasing consumption of natural gas imposes a need to facilitate the handling and distribution of the fuel, which presently is compressed or condensed. Alternatively, reduced volatility and increased tractability are achieved by converting the chemical energy of the main component, methane, into liquid methanol. Previous studies have explored direct methane-to-methanol conversion, but suitable catalysts have not yet been identified. Here, the complete reaction cycle for methaneto-methanol conversion over the Cu-SSZ-13 system is studied using density functional theory. The first step in the reaction cycle is the migration of $\mathrm{Cu}$ species along the zeolite framework forming the $\mathrm{Cu}$ pair, which is necessary for the adsorption of $\mathrm{O}_{2}$. Methane

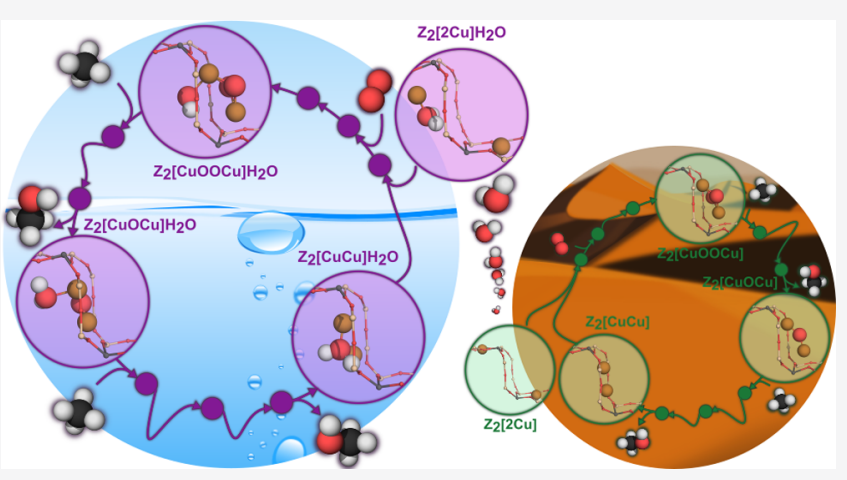
conversion occurs over the $\mathrm{CuOOCu}$ and $\mathrm{CuOCu}$ sites, consecutively, after which the system is returned to its initial structure with two separate $\mathrm{Cu}$ ions. A density functional theorybased kinetic model shows high activity when water is included in the reaction mechanism, for example, even at very low partial pressures of water, the kinetic model results in a turnover frequency of $\sim 1$ at $450 \mathrm{~K}$. The apparent activation energy from the kinetic model $(\sim 1.1 \mathrm{eV})$ is close to recent measurements. However, experimental studies always observe very small amounts of methanol compared to formation of more energetically preferred products, for example, $\mathrm{CO}_{2}$. This low selectivity to methanol is not described by the current reaction mechanism as it does not consider formation of other species; however, the results suggest that selectivity, rather than inherent kinetic limitations, is an important target for improving methanol yields from humid systems. Moreover, a closed reaction cycle for the partial oxidation of methane has long been sought, and in achieving this over the Cu-SSZ-13, this study contributes one more step toward identifying a suitable catalyst for direct methane-to-methanol conversion.

\section{INTRODUCTION}

Natural gas is the third-largest primary energy source, and given that its main component is methane, it is crucial to continually keep the gas under high pressure $(20-25 \mathrm{MPa})$ or low temperature $\left(-163{ }^{\circ} \mathrm{C}\right)$ to reduce its volatility and increase tractability. Converting methane into methanol would retain high specific energy and low carbon emission of methane while keeping the fuel in liquid form at room temperature and removing the need for constant temperature or pressure control. However, direct methane-to-methanol (DMTM) conversion is a notoriously difficult reaction, and a suitable catalytic system for the reaction is yet to be identified. The issue with the DMTM reaction is that complete methane combustion to $\mathrm{CO}_{2}$ and $\mathrm{H}_{2} \mathrm{O}$ is thermodynamically preferred, and the catalyst should, thus, have selectivity toward $\mathrm{CH}_{3} \mathrm{OH}$.

One line of research has been trying to mimic the porous structure and ionic metal sites of the naturally occurring enzymatic methane monooxygenases ${ }^{1}$ by metal ion-exchanging zeolites. Several zeolite structures, such as ZSM-5 and SSZ-13, have shown promising signs of enhancing the reaction. ${ }^{2-8}$ However, the exact structure and function of these catalytic materials are not yet known. Experimental studies of DMTM conversion over zeolite systems have successfully produced methanol using a three-step cyclic procedure. The first step is the introduction of oxidants (e.g., $\mathrm{O}_{2}, \mathrm{~N}_{2} \mathrm{O}$, or $\mathrm{NO}$ ) at high temperature $\left(>350^{\circ} \mathrm{C}\right)$. The second step is the reaction phase at $50-210{ }^{\circ} \mathrm{C}$, where $\mathrm{CH}_{4}$ is introduced. The last step is the extraction at $25-210{ }^{\circ} \mathrm{C}$, where reactants and products are extracted using a solvent such as water or ethanol. ${ }^{2,5,9}$ Using this method, Cu-SSZ-13 has been shown to yield 28-31 $\mu \mathrm{mol}_{\mathrm{CH}_{3} \mathrm{OH}} g_{\text {cat }}^{-1}$, where the lower yield corresponds to a lower $\mathrm{Si} / \mathrm{Al}$ ratio in the zeolite. ${ }^{9}$ Recently, it has also been shown that conversion can be achieved in a continuous manner, where after pretreating the catalyst at a high temperature $(\sim 800 \mathrm{~K})$, the reaction is performed continuously at $\sim 500 \mathrm{~K},{ }^{10}$ where SSZ-13 has been reported to produce $3.13 \mu \mathrm{mol}_{\mathrm{CH}_{3} \mathrm{OH}} h^{-1} g_{\text {cat }}^{-16}$ In

Received: May 7, 2021

Revised: June 21, 2021

Published: July 5, 2021

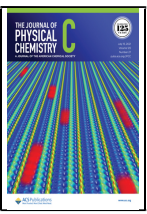


addition to the use of water as a solvent, recent findings identify $\mathrm{H}_{2} \mathrm{O}$ as an oxidant in the reaction under anaerobic conditions. ${ }^{11,12}$ The use of water as an oxidant might increase the selectivity of the site as $\mathrm{H}_{2} \mathrm{O}$ acts as a milder oxidant compared to $\mathrm{O}_{2}{ }^{13}$

Copper seems to be one of the most promising candidates for the reaction over ion-exchanged zeolites, and several different active-site motifs have been investigated and proposed as responsible for the conversion. ${ }^{14-16}$ Several structures have been suggested, such as $\mathrm{CuOH}, \mathrm{CuOOCu}$, and $\mathrm{CuOCu} .{ }^{17-20}$ Dinh et al. ${ }^{10}$ propose the $\mathrm{CuOCu}$ structure as being the activesite structure showing selectivity toward methane formation, while other $\mathrm{Cu}$ structures and $\mathrm{Cu}_{x} \mathrm{O}_{y}$ clusters promote complete $\mathrm{CH}_{4}$ oxidation to $\mathrm{CO}_{2}$. A proposed mechanism for the formation of the $\mathrm{CuOOCu}$ and $\mathrm{CuOCu}$ structures is via a $\mathrm{CuOH}$ intermediate, ${ }^{19}$ where an intermediate $\mathrm{CuO}$ structure is also proposed to be promoting $\mathrm{CH}_{4}$ conversion ${ }^{21}$ (however, a stable $\mathrm{CuO}$ structure in the zeolite has not been observed experimentally). Additionally, the formation of the dimeric structures is proposed to be sensitive to the $\mathrm{Si} / \mathrm{Al}$ ratio (according to Ipek et al., ${ }^{19}$ where a low ratio of $\mathrm{Si} / \mathrm{Al} \approx 12$ was preferred for $\mathrm{CH}_{3} \mathrm{OH}$ production), as well as the $\mathrm{Al}-\mathrm{Al}$ distance in the zeolite cage. ${ }^{22}$ Larger trimer motifs, although not prevalent in the small-pore zeolites, are found in zeolites such as MOR and MFI. ${ }^{23}$ In addition to trimer sites, multiple interacting monomer complexes have been identified in zeolites MOR and MAZ. These interacting $[\mathrm{CuOH}]^{+}$sites, prevalent at high $\mathrm{Si} / \mathrm{Al}$ ratios, have been suggested to be responsible for the highly selective conversion in large-pore zeolites. ${ }^{24,25}$

In this study, we use first-principles calculations to determine the mechanism in forming the active site. The identified DMTM reaction occurs over the $\mathrm{CuOOCu}$ and $\mathrm{CuOCu}$ structures, and the activity is investigated using a microkinetic model calculating the turnover frequency (TOF) for a continuous reaction cycle. As the presence of water is believed to influence the reaction, ${ }^{11,16,26,27}$ the partial pressure of water is included in a microkinetic model of the activity for the reaction.

\section{METHODS}

Density functional theory calculations were performed using the Vienna Ab initio Simulation Package (VASP) ${ }^{28-33}$ where the projector augmented wave (PAW) method ${ }^{34,35}$ models the interaction between the valence electrons and the cores. PAW potentials were used with the valence states $\mathrm{H}\left(1 \mathrm{~s}^{1}\right), \mathrm{O}\left(2 \mathrm{~s}^{2} 2 \mathrm{p}^{4}\right)$, $\mathrm{C}\left(2 \mathrm{~s}^{2} 2 \mathrm{p}^{2}\right), \quad \mathrm{Al}\left(3 \mathrm{~s}^{2} 3 \mathrm{p}^{1}\right), \quad \mathrm{Si}\left(3 \mathrm{~s}^{2} 3 \mathrm{p}^{2}\right)$, and $\mathrm{Cu}\left(3 \mathrm{~d}^{10} 4 \mathrm{~s}^{1}\right)$. The exchange-correlation interaction was treated using the vdWDF-cx functional, ${ }^{36-38}$ which includes van der Waals interactions into the exchange-correlation by taking nonlocal screening into account. The effect of using a $+U$ correction, $U$ $=6 \mathrm{eV}$, is shown in Figures S2 and S3 for the dry and wet reaction, respectively. The Kohn-Sham orbitals were represented using a plane-wave basis set with $480 \mathrm{eV}$ as the cutoff energy. A Gaussian smearing of $0.05 \mathrm{eV}$ was applied to the Fermi level discontinuity. The electronic energies were converged to $10^{-8} \mathrm{eV}$ in the self-consistent loop, and ionic positions were considered to be relaxed when the largest atomic force in the system was smaller than $0.02 \mathrm{eV} / \AA$. The Brillouin zone was sampled using the $\Gamma$-point approximation. The gas-phase molecules were treated in a cubic box with sides of $10 \AA$. All calculations were done using spin polarization. The transition states (TS) were obtained using the climbing NEB method, ${ }^{39-41}$ as implemented in VASP. During the NEB, the spin of the structure was allowed to change.
Vibrational energies were calculated by constructing the Hessian matrix using atomic forces generated by $0.01 \AA$ displacements of the considered atoms. Only the extraframework atoms, that is, the active site and reactants, were included in the vibration analysis. All low-lying normal modes (including negative modes) of the adsorbed reaction intermediate were set to $100 \mathrm{~cm}^{-1}$. The translations and rotations of gas-phase water, methane, and methanol were calculated using the ideal gas approximation, whereas all vibrations were calculated using the harmonic approximation. ${ }^{42,43}$ Rotations were treated by the rigid motor model. ${ }^{44}$ All intermediate states have been analyzed for charge distribution using the Bader analysis method developed by the Henkelman group. ${ }^{45-48}$

The stability of the reaction intermediate states was compared using the change in Gibbs free energy

$$
\Delta G(T, \Delta \mu)=\Delta H-T \cdot \Delta S(T)-\Delta \mu
$$

$T$ is temperature, and $\Delta \mu$ is the change in chemical potential between $0 \mathrm{~K}$ and the condition of interest for the relevant gases. Here, $\Delta \mu=\Delta \mu_{\mathrm{CH}_{4}}$ unless water is added into the mechanism, in which case, $\mathrm{H}_{2} \mathrm{O}$ is treated in an analogous way to $\mathrm{CH}_{4}$ in eq 2, and $\Delta \mu$.

$\Delta S$ is the difference in entropy between adsorbed and gasphase states

$$
\Delta S=S_{\text {adsorbed }}-S_{\text {gas-phase }}
$$

When gas-phase molecules are present in the zeolite cage, their entropy contribution is affected by the confinement of the zeolite structure and is calculated according to ${ }^{49,50}$

$$
S^{\mathrm{zeo}}=\frac{2}{3}\left(S_{\text {trans }}^{\mathrm{gas}}+S_{\mathrm{rot}}^{\mathrm{gas}}\right)+S_{\mathrm{vib}}^{\mathrm{zeo}}
$$

Here, $S_{\text {trans }}^{\text {gas }}$ and $S_{\text {rot }}^{\text {gas }}$ are entropy contributions from the gas-phase translations and rotations of the molecule, and $S_{\text {vib }}^{\text {zeo }}$ is the entropy contribution from the vibrational modes of the molecule inside the zeolite. In eq 1, the change in enthalpy is approximated as the difference in total energy. ${ }^{51}$

Microkinetic Modeling. The implications of the methaneto-methanol energy landscapes were explored further using a mean-field microkinetic model.

The rate constants are expressed using the conventional transition-state theory ${ }^{44}$

$$
k_{\mathrm{TST}}=\frac{k_{\mathrm{B}} T}{h} \frac{Z^{\prime}}{Z} \exp \left(-\frac{\Delta E}{k_{\mathrm{B}} T}\right)=\frac{k_{\mathrm{B}} T}{h} \exp \left(-\frac{\Delta G}{k_{\mathrm{B}} T}\right)
$$

where $\Delta E$ is the energy difference between the initial state and transition state, $Z$ is the partition function for the initial state, $Z^{\prime}$ is the partition function for the transition state with the reaction coordinate excluded, $k_{\mathrm{B}}$ is Boltzmann's constant, and $h$ is Planck's constant. The free energy differences, $\Delta G$, were computed in the harmonic approximation for all adsorbates except methane and water and by the ideal gas approximation for gas molecules. Methane and water molecules present in the zeolite channel were treated as hindered gases, retaining twothirds of their translational and rotational entropy, ${ }^{49,50}$ as given in eq 3. The adsorption/desorption of methane, methanol, and water were considered to be barrierless, and the rate constant for adsorption was calculated as

$$
k_{\mathrm{ads}}=\frac{p A}{\left(2 \pi m k_{\mathrm{B}} T\right)^{1 / 2}}
$$




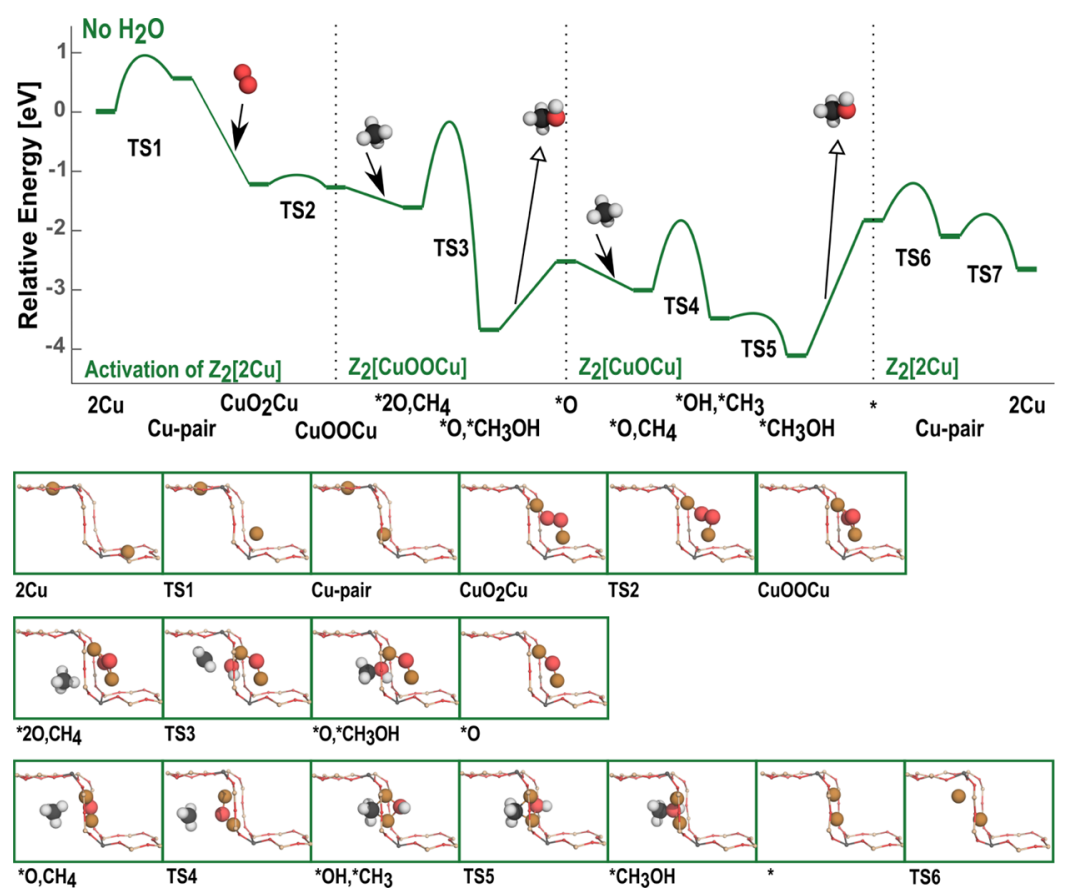

Figure 1. Dry reaction path. The first part of the reaction is the activation of the $\mathrm{Z}_{2}[2 \mathrm{Cu}]$ system using $\mathrm{O}_{2}$. The DMTM reaction is performed over the activated $\mathrm{Z}_{2}[\mathrm{CuOOCu}]$ and subsequently over $\mathrm{Z}_{2}[\mathrm{CuOCu}]$, producing two $\mathrm{CH}_{3} \mathrm{OH}$ molecules per complete cycle. The very last step is a barrierless, exothermic regeneration of the initial $2 \mathrm{Cu}$ structure. The energies are in electron volts and relative to that of $\mathrm{Z}_{2}[2 \mathrm{Cu}]$, with two $\mathrm{CH}_{4}$ and one $\mathrm{O}_{2}$ in the gas phase. Atom color code: copper (brown), oxygen (red), hydrogen (white), carbon (black), silicon (beige), and aluminum (gray).

where $p$ is the partial pressure of the molecule in the gas phase, $A$ is the cross-sectional area of the pore consistent with similar studies, $^{52,53}$ and $m$ the mass of the molecule. The corresponding desorption rate constants were obtained through the equilibrium constant

$$
K_{\mathrm{eq}}=\frac{k_{\mathrm{ads}}}{k_{\mathrm{des}}}=\exp \left(-\frac{\Delta G}{k_{\mathrm{B}} T}\right)
$$

The differential equations were solved in Python, using the SciPy ${ }^{54}$ lsoda wrapper to the Fortran ODEPACK library, ${ }^{55}$ and backward differentiation formulas. The relative and absolute tolerances were set to $1 \times 10^{-8}$ and $1 \times 10^{-10}$, respectively. Steady states were checked using the root-finding solver in SciPy with the hybr method, which is a modified version of the Powell hybrid method from MINPACK, ${ }^{56}$ with a relative error tolerance of $1 \times 10^{-8}$.

Zeolite Framework. In this study, partial oxidation of methane to methanol is investigated over the $\mathrm{Cu}$-functionalized chabazite (CHA) framework SSZ-13. The SSZ-13 is a smallpored zeolite consisting of four-, six-, and eight-membered rings (MRs). Considering the hexagonal unit cell of the CHA framework with 36 tetrahedral sites (see Figure S1), an Si/Al ratio of $36: 2$ is used and is denoted $\mathrm{Z}_{2}$. Two $\mathrm{Cu}$ ions are introduced to compensate for the +2 charge in the $\mathrm{Z}_{2}$ zeolite system.

\section{RESULTS AND DISCUSSION}

The reaction mechanism for the full reaction cycle is explored for the DMTM reaction over Cu-SSZ-13. For simplicity, the full cycle will be divided into three parts, (i) the activation phase, which forms $\mathrm{Cu}$ dimers from two separate $\mathrm{Cu}$ ions, (ii) the reaction phase where methane interacts with the $\mathrm{Z}_{2}[\mathrm{CuOOCu}]$ and $\mathrm{Z}_{2}[\mathrm{CuOCu}]$ sites, and produce methanol, and finally (iii) the extraction phase, where the formation of separate $\mathrm{Cu}$ ions occurs after desorbing the second methanol in the cycle.

In the description of intermediate steps, two different notations are used. During the activation phase, the notation is chosen to emphasize the structure of the $\mathrm{Cu}$ ions. During reaction and extraction, the two $\mathrm{Cu}$ ions of the active site are located in the $8 \mathrm{MR}$ and denoted as *. Hence, $* \mathrm{X}, \mathrm{Y}$ implies that reaction intermediate $\mathrm{X}$ is coordinated to the $\mathrm{Cu}$ ions, forming the current state of the active site, while reaction intermediate $\mathrm{Y}$ is either adsorbed on the active site or is free in the zeolite. Vibrations of all intermediate states, for dry and wet conditions, can be found in the Supporting Information: activation intermediates in Table $S 1$, intermediates for reaction and extraction over $\mathrm{Z}_{2}[\mathrm{CuOOCu}]$ in Table $\mathrm{S} 2$, and intermediates for reaction and extraction over $\mathrm{Z}_{2}[\mathrm{CuOCu}]$ in Table S3. The structural properties of gas-phase $\mathrm{O}_{2}, \mathrm{H}_{2} \mathrm{O}, \mathrm{CH}_{4}$, and $\mathrm{CH}_{3} \mathrm{OH}$ are in good agreement with experimental values; ${ }^{57}$ for details, see Table S4. The formation energy of the DMTM conversion is $0.534 \mathrm{eV}$ higher when calculated using the vdW-DF-cx functional as compared to the experimental value reported by Gurvich et al. ${ }^{58}$ Comparison with other functionals can be found in Table S5.

Reaction Cycle during Dry Conditions. The energy landscape for activation of $\mathrm{Z}_{2}[2 \mathrm{Cu}]$ is shown along with the subsequent DMTM reactions in Figure 1. The most stable structure is when the system contains only two $\mathrm{Cu}$ ions (i.e., $2 \mathrm{Cu}$ in Figure 1), with one $\mathrm{Cu}$ ion in each of the $6 \mathrm{MR}$. The highest barrier in the activation of the system is the migration of one of the $\mathrm{Cu}$ ions from the $6 \mathrm{MR}$ to the nearest $8 \mathrm{MR}$ containing two $\mathrm{Al}$ atoms (i.e., TS1). Moving of the $\mathrm{Cu}$ ion through the zeolite is associated with a barrier of $0.95 \mathrm{eV}$. This is $0.20 \mathrm{eV}$ more than when using BEEF as the exchange-correlation functional. ${ }^{59}$ This higher barrier is likely a result of the known tendency of vdW-DF-cx to overbind when compared to PBE; BEEF, on the 
other hand, often does the opposite and underestimates the stability of the structure. ${ }^{60}$ After the forming the $\mathrm{Cu}$-pair intermediate, $\mathrm{O}_{2}$ is included as the second $\mathrm{Cu}$ ion moves to the same $8 \mathrm{MR}$ in a $1.79 \mathrm{eV}$ exothermic formation of $\mathrm{CuO}_{2} \mathrm{Cu}$. As oxygen is added to the $\mathrm{Cu}$ dimer, the most stable position for $\mathrm{Cu}_{2} \mathrm{O}_{2}$ is in the plane of the $8 \mathrm{MR}$ containing two $\mathrm{Al}$ atoms; insertion of the oxygen into the zeolite cage is assumed to be barrierless, and thus, the formation of the $\mathrm{CuO}_{2} \mathrm{Cu}$ in the $8 \mathrm{MR}$ occurs without a barrier. The last step in the activation forms the most stable possible structure of $\mathrm{Cu}_{2} \mathrm{O}_{2}$ in the zeolite, the symmetric structure of $\mathrm{CuOOCu}$. The barrier for $\mathrm{CuOOCu}$ formation is $0.16 \mathrm{eV}$. The presence of the $\mathrm{CuOOCu}$ structure for DMTM has been shown experimentally in the zeolite structure ZSM-5. ${ }^{5}$ The conversion to methanol is known to occur via the $\mathrm{CH}_{3}$ radical. ${ }^{61}$ Hence after the addition of $\mathrm{CH}_{4}$ into the zeolite, the reaction over the $\mathrm{Z}_{2}[\mathrm{CuOOCu}]$ system is limited by TS3. The $\mathrm{CH}_{3}$ radical of TS3 forms with a barrier of $1.44 \mathrm{eV}$, after which $* \mathrm{O}, * \mathrm{CH}_{3} \mathrm{OH}$ forms on the $\mathrm{Cu}$ dimer. Formation of the second $\mathrm{CH}_{3} \mathrm{OH}$, now over $\mathrm{Z}_{2}[\mathrm{CuOCu}]$, is governed by TS4, which again is associated with the activation of $\mathrm{CH}_{4}$. Over the $\mathrm{Z}_{2}[\mathrm{CuOCu}]$ system, the barrier to form the $\mathrm{CH}_{3}$ radical is 1.17 $\mathrm{eV}$, which is $0.27 \mathrm{eV}$ lower than that over the $\mathrm{Z}_{2}[\mathrm{CuOOCu}]$ system. The lower barrier to form the radical over $\mathrm{Z}_{2}[\mathrm{CuOCu}]$ as compared to $\mathrm{Z}_{2}[\mathrm{CuOOCu}]$ is in accordance with $\mathrm{Zhao} \mathrm{et} \mathrm{al.}{ }^{18}$ Forming $\mathrm{CH}_{3} \mathrm{OH}$ over $\mathrm{Z}_{2}[\mathrm{CuOCu}]$ requires moving the $\mathrm{OH}$ group through the $8 \mathrm{MR}$, which is associated with a barrier of $0.08 \mathrm{eV}$. The final desorption of $\mathrm{CH}_{3} \mathrm{OH}$ has a barrier of $2.29 \mathrm{eV}$. After the desorption of the second $\mathrm{CH}_{3} \mathrm{OH}$, the two $\mathrm{Cu}$ ions in the $8 \mathrm{MR}$ return to the $\mathrm{Z}_{2}$ [Cu-pair] configuration with one $\mathrm{Cu}$ ion in the $6 \mathrm{MRs}$ over a barrier of $0.64 \mathrm{eV}$. A return to the initial structure $2 \mathrm{Cu}$, that is, both $\mathrm{Cu}$ ions in $6 \mathrm{MRs}$, occurs via a barrier of $0.39 \mathrm{eV}$ (TS7). The overall change in energy $(2.67 \mathrm{eV})$ is the exothermicity of the reaction.

There are several spin flips between the singlet and triplet state during the reaction path outlined in Figure 1. Due to the change in spin (as shown in Table 1), the rate calculated for the reaction is an upper limit (for further discussion, see Shiota and Yoshizawa ${ }^{21}$ ). The energy difference between the lowest and second-lowest state is found in Table 1. The charge distribution

Table 1. Spin State of the Intermediates in the Activation Reaction Following the Reaction Mechanisms in Figure $1^{a}$

$\begin{array}{lcc}\text { reaction intermediate } & \text { spin state } & \text { energy difference }[\mathrm{eV}] \\ 2 \mathrm{Cu} & \text { singlet } & 2.69 \\ \mathrm{TS} 1 & \text { singlet } & 2.07 \\ \mathrm{Cu} \text {-pair } & \text { singlet } & 1.86 \\ \mathrm{CuO}{ }_{2} \mathrm{Cu} & \text { triplet } & 0.15 \\ \mathrm{TS} 2 & \text { triplet } & 0.31 \\ \mathrm{CuOOCu} & \text { singlet } & 0.10 \\ * 2 \mathrm{O}, \mathrm{CH}_{4} & \text { singlet } & 0.12 \\ \mathrm{TS} 3 & \text { triplet } & 1.01 \\ * \mathrm{O}, * \mathrm{CH}_{3} \mathrm{OH} & \text { triplet } & 0.19 \\ * \mathrm{O} & \text { triplet } & 0.14 \\ * \mathrm{O}, \mathrm{CH}_{4} & \text { singlet } & 0.01 \\ \mathrm{TS} 4 & \text { singlet } & 0.46 \\ * \mathrm{O},{ }^{*} \mathrm{CH}_{3} & \text { singlet } & 0.54 \\ \mathrm{TS} 5 & \text { singlet } & 0.67 \\ * \mathrm{CH} \mathrm{OH}_{3} & \text { singlet } & 1.75 \\ * & \text { singlet } & 0.78\end{array}$

${ }^{a}$ Energy difference between the two lowest spin states in electronvolts. of the $\mathrm{Cu}$ ions in each intermediate state can be found in Table S6.

Reaction Cycle during Wet Conditions. Zeolites are known to be very humid, and the presence of water has proven to be important for reactions in the zeolite. ${ }^{20,27}$ The dry mechanism as illustrated in Figure 1 might, thus, be affected by the addition of $\mathrm{H}_{2} \mathrm{O}$. Here, one $\mathrm{H}_{2} \mathrm{O}$ is introduced into the reaction mechanism and is allowed to interact with the reaction intermediates. The results show that in all cases, the $\mathrm{H}_{2} \mathrm{O}$ coordinates preferably with one of the $\mathrm{Cu}$ ions. The adsorption energy ranges from the lowest adsorption energy of $0.75 \mathrm{eV}$ on $\mathrm{TS} 4\left[\mathrm{H}_{2} \mathrm{O}\right]$ to the highest of $2.02 \mathrm{eV}$ on $*\left[\mathrm{H}_{2} \mathrm{O}\right]$.

The energy landscape for activation of $\mathrm{Z}_{2}[2 \mathrm{Cu}]$, with water included in the reaction, is shown in Figure 2. As opposed to the $2 \mathrm{Cu}$ system without $\mathrm{H}_{2} \mathrm{O}$, inclusion of water initially lifts one of the $\mathrm{Cu}$ ions from its position in the $6 \mathrm{MRs}$. This results in a 0.73 $\mathrm{eV}$ lower barrier for migration of the $\mathrm{Cu}$ from the $6 \mathrm{MR}$ to the 8 MR. As this first TS is the limiting step in the activation, the presence of water facilitates the activation of the system. The introduction of $\mathrm{O}_{2}$ again results in an exothermic formation of $\mathrm{CuO}_{2} \mathrm{Cu}$. However, $\mathrm{O}_{2}$ adsorption onto the $\mathrm{Cu}$ dimer is $0.91 \mathrm{eV}$ when including $\mathrm{H}_{2} \mathrm{O}$ that is adsorbed, which is $\sim 1 \mathrm{eV}$ less than that in the absence of water. Thus, during the activation phase of the reaction, $\mathrm{H}_{2} \mathrm{O}$ flattens the landscape by lowering the barriers and destabilizing the intermediates.

Dissociation of $\mathrm{CH}_{4}$ via the $\mathrm{CH}_{3}$ radical (TS2), followed by a strongly bound $\mathrm{CH}_{3} \mathrm{OH}$ on the $\mathrm{Cu}$ dimer $\left(* \mathrm{O}\right.$, ${ }^{*} \mathrm{CH}_{3} \mathrm{OH}-$ $\left.\left[\mathrm{H}_{2} \mathrm{O}\right]\right)$ has a barrier of $0.28 \mathrm{eV} . \mathrm{CH}_{4}$ dissociation over $\mathrm{Z}_{2}[\mathrm{CuOOCu}] \mathrm{H}_{2} \mathrm{O}$ has a barrier that is $1.16 \mathrm{eV}$ lower than that in the dry case. One $\mathrm{Cu}$ cation detaches from the framework when $\mathrm{CH}_{3} \mathrm{OH}$ is formed, indicating increased mobility of the wet cluster.

Formation of the second $\mathrm{CH}_{3} \mathrm{OH}$, over $\mathrm{Z}_{2}[\mathrm{CuOCu}]$, goes through TS3, the $\mathrm{CH}_{3}$ radical formation. The barrier to form the radical (TS3) is decreased by $0.7 \mathrm{eV}$ when $\mathrm{H}_{2} \mathrm{O}$ is added to the reaction as compared to the dry reaction. However, TS4, the formation of $* \mathrm{CH}_{3} \mathrm{OH}$, is increased by $0.28 \mathrm{eV}$ for the wet system as compared to the dry case. The mechanism for ${ }^{*} \mathrm{CH}_{3} \mathrm{OH}$ formation over $\mathrm{Z}_{2}[\mathrm{CuOCu}]$ in the wet system is different from the mechanism over the dry system. Instead of moving the $* \mathrm{OH}$ group through the $8 \mathrm{MR}$, the $* \mathrm{OH}$ detaches from one of the $\mathrm{Cu}$ ions and is rotated into the cage, where it is connected to the $* \mathrm{CH}_{3}$. The desorption energy of $\mathrm{CH}_{3} \mathrm{OH}$ is $1.22 \mathrm{eV}$. After the desorption of the second $\mathrm{CH}_{3} \mathrm{OH}$, the two $\mathrm{Cu}$ ions in the $8 \mathrm{MR}$ return to the $\mathrm{Z}_{2}$ [Cu-pair] configuration with one $\mathrm{Cu}$ ion in the $6 \mathrm{MRs}$ over a barrier of $0.96 \mathrm{eV}$. A return to the initial structure $2 \mathrm{Cu}$, that is, both $\mathrm{Cu}$ ions in $6 \mathrm{MRs}$, occurs via a barrier of $0.47 \mathrm{eV}$ (TS7).

There are two spin flips between the singlet and triplet state during the considered reaction path. Due to the change in spin (as shown in Table 2), the rate calculated for the reaction is also, in this case, an upper limit. The energy difference between the lowest and second-lowest state is given in Table 2. The charge distribution of the $\mathrm{Cu}$ ions in each intermediate state can be found in Table S6.

Kinetic Models. In order to study the kinetic performance of the dry and wet DMTM reaction mechanisms, we turn to meanfield microkinetic modeling based on the respective energy landscapes. The active sites are taken to begin in the $2 \mathrm{Cu}$ state (with/without water), and the activation, reaction, and desorption steps are included to result in a complete catalytic cycle, that is, ending in the $2 \mathrm{Cu}$ state (with/without water). The catalytic cycle is shown in Figure S4 in the Supporting 

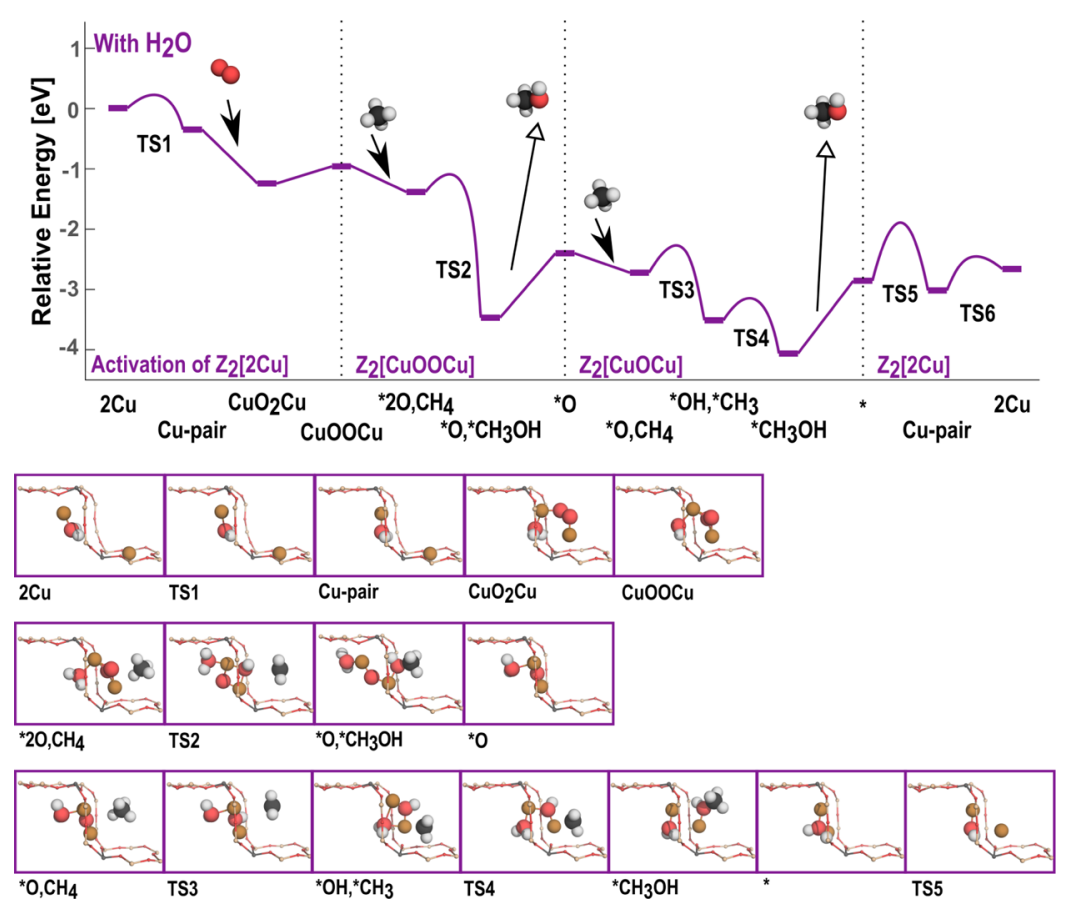

Figure 2. Reaction path including $\mathrm{H}_{2} \mathrm{O}$. The first part of the reaction is the activation of the $\mathrm{Z}_{2}[2 \mathrm{Cu}] \mathrm{H}_{2} \mathrm{O}$ system using $\mathrm{O}_{2}$. The DMTM reaction is performed over the activated $\mathrm{Z}_{2}[\mathrm{CuOOCu}] \mathrm{H}_{2} \mathrm{O}$ and, subsequently, over $\mathrm{Z}_{2}[\mathrm{CuOCu}] \mathrm{H}_{2} \mathrm{O}$, producing two $\mathrm{CH}_{3} \mathrm{OH}$ molecules per complete cycle. The very last step is a barrierless, endothermic regeneration of the initial $2 \mathrm{Cu}$ structure. The energies are in electronvolts and relative to that of $\mathrm{Z}_{2}[2 \mathrm{Cu}] \mathrm{H}_{2} \mathrm{O}$, with two $\mathrm{CH}_{4}$ and one $\mathrm{O}_{2}$ in the gas phase. Atom color code: copper (brown), oxygen (red), hydrogen (white), carbon (black), silicon (beige), and aluminum (gray).

Table 2. Spin State of the Intermediates in the Activation Reaction with $\mathrm{H}_{2} \mathrm{O}$ Following the Reaction Mechanisms in Figure $2^{a}$

$\begin{array}{lcc}\text { reaction intermediate } & \text { spin state } & \text { energy difference }[\mathrm{eV}] \\ 2 \mathrm{Cu}\left[\mathrm{H}_{2} \mathrm{O}\right] & \text { singlet } & 2.77 \\ \mathrm{TS} 1\left[\mathrm{H}_{2} \mathrm{O}\right] & \text { singlet } & 3.31 \\ \mathrm{Cu}-\text { pair }\left[\mathrm{H}_{2} \mathrm{O}\right] & \text { singlet } & 2.65 \\ \mathrm{CuO} \mathrm{O}_{2} \mathrm{Cu}\left[\mathrm{H}_{2} \mathrm{O}\right] & \text { triplet } & 0.31 \\ \mathrm{CuOOCu}\left[\mathrm{H}_{2} \mathrm{O}\right] & \text { triplet } & 0.28 \\ * 2 \mathrm{O}, \mathrm{CH}_{4}\left[\mathrm{H}_{2} \mathrm{O}\right] & \text { triplet } & 0.11 \\ \mathrm{TS} 2\left[\mathrm{H}_{2} \mathrm{O}\right] & \text { triplet } & 0.55 \\ * \mathrm{O}, * \mathrm{CH}_{3} \mathrm{OH}\left[\mathrm{H}_{2} \mathrm{O}\right] & \text { triplet } & 0.09 \\ * \mathrm{O}\left[\mathrm{H}_{2} \mathrm{O}\right] & \text { triplet } & 0.09 \\ * \mathrm{O}, \mathrm{CH}_{4}\left[\mathrm{H}_{2} \mathrm{O}\right] & \text { triplet } & 0.03 \\ \mathrm{TS} 3\left[\mathrm{H}_{2} \mathrm{O}\right] & \text { singlet } & 1.70 \\ * \mathrm{O}, * \mathrm{CH} \mathrm{H}_{3}\left[\mathrm{H}_{2} \mathrm{O}\right] & \text { singlet } & 0.91 \\ \mathrm{TS} 4\left[\mathrm{H}_{2} \mathrm{O}\right] & \text { singlet } & 0.93 \\ * \mathrm{CH} \mathrm{H}_{3} \mathrm{OH}\left[\mathrm{H}_{2} \mathrm{O}\right] & \text { singlet } & 2.18 \\ *\left[\mathrm{H}_{2} \mathrm{O}\right] & \text { singlet } & 1.92\end{array}$

${ }^{a}$ Energy difference between the two lowest spin states in electron volts.

Information. The steady-state distribution of intermediates is found to be similar in the dry and wet systems (Figure 3a). The dominant intermediate under most reaction temperatures is adsorbed methanol $\left(* \mathrm{CH}_{3} \mathrm{OH}\right)$ because methanol desorption is significantly endergonic in the dry system and in the wet system below $640 \mathrm{~K}$. The portion of sites occupied by methane on $\mathrm{Z}_{2}[\mathrm{CuOCu}]$ and, to a lesser extent, $\mathrm{Z}_{2}[\mathrm{CuOOCu}]$ increases with temperature as the adsorbed methane states are less destabilized by increasing temperature than their subsequent TS and adsorbed methanol states, that is, the reaction barriers increase and the reaction free energy becomes more positive/ less negative.

The TOF of the wet system is found to be significantly higher than that of the dry system at all temperatures (Figure $3 b$ ). While the wet system can achieve a TOF of $1 \mathrm{~s}^{-1}$ at a temperature of $440 \mathrm{~K}$, the dry system is much less active across the full temperature range investigated, only yielding a TOF 12 orders of magnitude lower at the same temperature and never reaching $1 \mathrm{~s}^{-1}$ (the chabazite framework is only stable below ca. $\left.800 \mathrm{~K}^{62}\right)$. The impact of water on the performance of the $\mathrm{Cu}$ SSZ-13 catalyst can be investigated further by combining the dry and wet mechanisms, allowing adsorption of water to the initially dry active sites and enabling both pathways simultaneously (see dotted arrow in Figure S4). This implies that the $\mathrm{Cu}$-sites can be either dry or wet depending on whether they have taken up a water molecule. $\mathrm{Cu}$ sites in a dry state will exhibit the slow kinetics of the dry system, while the productivity of wet sites should be accelerated. The kinetics are found to be strongly dependent on both temperature and the partial pressure of water (Figure 4). Because the catalytic cycle is significantly more favorable when the active sites are associated with an $\mathrm{H}_{2} \mathrm{O}$ molecule, a small water presence (around $10^{-7} \mathrm{bar}$ ) is found to be enough to achieve a reasonable TOF at $450 \mathrm{~K}$.

The presented computational model is tractable and straightforward but contains some significant limitations compared with the real system. First, the reaction mechanism does not include diffusion of active site species, reactants, or products inside the zeolite. Second, the model only includes one type of active site, thus ignoring the effect of competing active sites (e.g., $\mathrm{Cu}$ monomers, trimers, and Brønsted sites), impurities, defects, and spectator species. Third, no competing reactions are included in the analysis, that is, only the activity for methanol formation is investigated. These limitations result in 
(a)
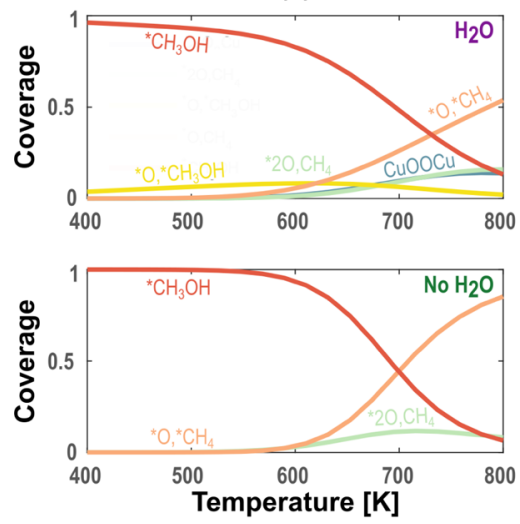

(b)

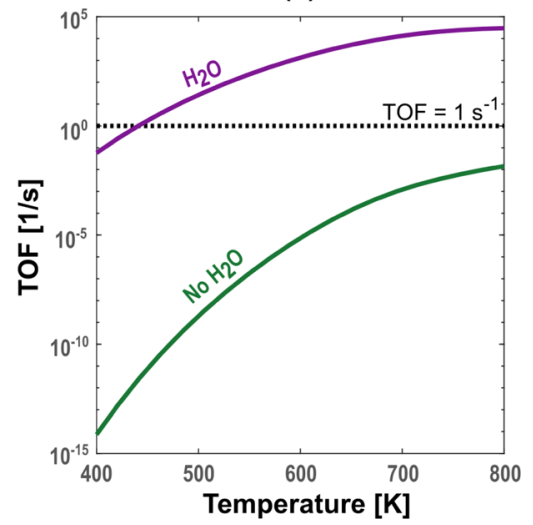

Figure 3. Steady-state kinetics predicted by density functional theory-based, mean-field models for the $\operatorname{dry}\left(\right.$ no $\left.\mathrm{H}_{2} \mathrm{O}\right)$ and wet $\left(\mathrm{H}_{2} \mathrm{O}\right)$ systems with $p_{\mathrm{CH}_{4}}$ $=2 \%, p_{\mathrm{O}_{2}}=10 \%, p_{\mathrm{CH}_{3} \mathrm{OH}}=10^{-9} \%$ at atmospheric pressure. (a) Temperature-dependent distribution of states with more than $1.5 \%$ coverage. (b) TOF obtained for the dry and wet mechanisms. The dotted line indicates TOF $=1 \mathrm{~s}^{-1}$.

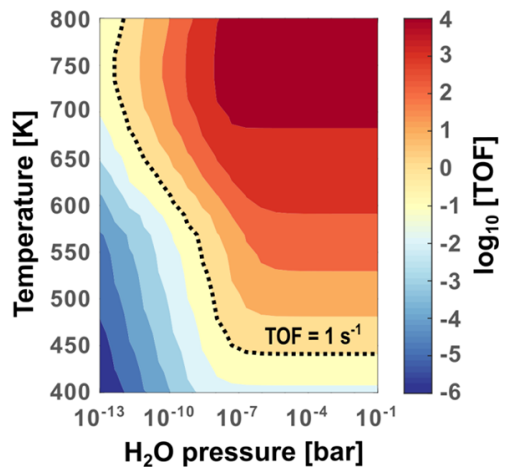

Figure 4. Logarithm of the TOF as a function of temperature and the partial pressure of water for combined wet and dry mechanisms with $p_{\mathrm{CH}_{4}}=2 \%, p_{\mathrm{O}_{2}}=10 \% p_{\mathrm{CH}_{3} \mathrm{OH}}=10^{-9} \%$ at atmospheric pressure after $10^{6}$ $\mathrm{s}$. The dotted contour highlights the conditions for which TOF $=1 \mathrm{~s}^{-1}$.

some important differences with respect to experimental observations. For instance, experiments report low quantities of methanol and instead observe significant quantities of $\mathrm{CO}$ and $\mathrm{CO}_{2},{ }^{10,63}$ which are reaction products not included in the present model.

However, looking past these limitations, the computational study provides an atomistic understanding of the effect of, for example, how water assists in the reaction. Furthermore, we find that under the conditions at which the TOF is close to $1 \mathrm{~s}^{-1}$, the apparent activation energy is estimated to be around $110 \mathrm{~kJ}$. $\mathrm{mol}^{-1}$, which is in qualitative agreement with experimental value of $100 \pm 2.1 \mathrm{~kJ} \cdot \mathrm{mol}^{-1}$ reported by Narsimhan. ${ }^{64}$ The low apparent activation energy for DMTM is promising for the activity of the Cu-SSZ-13 system, and the challenge is to find ways to limit the competing reactions to more stable products.

\section{CONCLUSIONS}

The complete reaction mechanisms and the activity of DMTM conversion in $\mathrm{Cu}$-SSZ-13 have been explored by first-principles calculations and microkinetic modeling under dry and wet conditions. Under both conditions, the activation of the system is initiated by the migration of $\mathrm{Cu}$ ions along the zeolite framework, consequently forming $\mathrm{Cu}$ dimers, which facilities the adsorption of $\mathrm{O}_{2}$. The subsequent DMTM reaction is performed over the activated $\mathrm{CuOOCu}$ and $\mathrm{CuOCu}$ sites, consecutively.
Over both sites, the dissociation of methane occurs via a methyl radical state, which is responsible for the highest barrier of the reaction during both dry and wet conditions. The addition of water into the system flattens the overall energy landscape, lowering the barriers, and facilitates desorption as the $\mathrm{H}_{2} \mathrm{O}$ molecules appear to increase the mobility of the active site. The microkinetic model suggests that the water-containing system is suitable for the partial oxidation reaction. The kinetics are positively affected by the temperature and partial pressure of water; even a very low humidity $\left(10^{-7}\right.$ bar $)$ in the system proves enough to produce a reasonable TOF at experimental reaction temperatures $(450 \mathrm{~K})$, and the predicted activation energy agrees well with the value observed experimentally. These results suggest that the system may be hindered by $\mathrm{CO}$ and $\mathrm{CO}_{2}$ formation, resulting in experimental rates lower than those predicted by kinetics based on the energy landscape for DMTM in isolation.

\section{ASSOCIATED CONTENT}

\section{SI Supporting Information}

The Supporting Information is available free of charge at https://pubs.acs.org/doi/10.1021/acs.jpcc.1c04062.

Detailed structure of SSZ-13, vibrational frequencies of reaction intermediates and gas-phase molecules, enthalpy of formation for methane-to-methanol conversion using different functionals, charge analysis of $\mathrm{Cu}$ ions in each intermediate state, energy landscapes including a $+U$ correction, and catalytic cycles used in kinetics study (PDF)

All identified intermediate states (ZIP)

\section{AUTHOR INFORMATION}

\section{Corresponding Authors}

Unni Engedahl - Department of Physics and Competence Centre for Catalysis, Chalmers University of Technology, SE 41296 Göteborg, Sweden; 이이.org/0000-0002-18716010; Email: unni@chalmers.se

Anders Hellman - Department of Physics and Competence Centre for Catalysis, Chalmers University of Technology, SE 41296 Göteborg, Sweden; (1) orcid.org/0000-0002-1821159X; Email: anders.hellman@chalmers.se 


\section{Authors}

Astrid Boje - Department of Physics, Chalmers University of

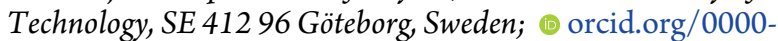
0002-2487-0276

Henrik Ström - Department of Mechanics and Maritime Sciences, Chalmers University of Technology, SE 41296 Göteborg, Sweden; 이이. orcid.org/0000-0002-8581-5174

Henrik Grönbeck - Department of Physics and Competence Centre for Catalysis, Chalmers University of Technology, SE 41296 Göteborg, Sweden; (1) orcid.org/0000-0002-87092889

Complete contact information is available at: https://pubs.acs.org/10.1021/acs.jpcc.1c04062

\section{Notes}

The authors declare no competing financial interest.

\section{ACKNOWLEDGMENTS}

Financial support is gratefully acknowledged from the Knut and Alice Wallenberg Foundation through the projects "Atomistic design of catalysts" (no: KAW 2015.0058), "Single particle catalysis in nanoreactors" (no: KAW 2015.0057) and the Competence Centre for Catalysis (KCK) at the Chalmers University of Technology. KCK is financially supported by the Chalmers University of Technology, the Swedish Energy Agency, and the member companies: A.B. Volvo, ECAPS A.B., Johnson Matthey A.B., Preem A.B., Scania CV A.B., and Umicore Denmark ApS. Calculations were performed at C3SE at Chalmers, with CPU time provided through a SNIC grant.

\section{REFERENCES}

(1) Sirajuddin, S.; Rosenzweig, A. C. Enzymatic Oxidation of Methane. Biochemistry 2015, 54, 2283-2294.

(2) Wang, X.; Martin, N.; Nilsson, J.; Carlson, S.; Gustafson, J.; Skoglundh, M.; Carlsson, P.-A. Copper-Modified Zeolites and Silica for Conversion of Methane to Methanol. Catalysts 2018, 8, 545.

(3) Newton, M. A.; Knorpp, A. J.; Pinar, A. B.; Sushkevich, V. L.; Palagin, D.; van Bokhoven, J. A. On the Mechanism Underlying the Direct Conversion of Methane to Methanol by Copper Hosted in Zeolites; Braiding Cu K-Edge XANES and Reactivity Studies. J. Am. Chem. Soc. 2018, 140, 10090-10093.

(4) Li, G.; Vassilev, P.; Sanchez-Sanchez, M.; Lercher, J. A.; Hensen, E. J. M.; Pidko, E. A. Stability and reactivity of copper oxo-clusters in ZSM-5 zeolite for selective methane oxidation to methanol. J. Catal. 2016, 338, 305-312.

(5) Groothaert, M. H.; Smeets, P. J.; Sels, B. F.; Jacobs, P. A.; Schoonheydt, R. A. Selective Oxidation of Methane by the $\operatorname{Bis}(\mu$ oxo)dicopper Core Stabilized on ZSM-5 and Mordenite Zeolites. J. Am. Chem. Soc. 2005, 127, 1394-1395.

(6) Narsimhan, K.; Iyoki, K.; Dinh, K.; Román-Leshkov, Y. Catalytic Oxidation of Methane into Methanol over Copper-Exchanged Zeolites with Oxygen at Low Temperature. ACS Cent. Sci. 2016, 2, 424-429.

(7) Pappas, D. K.; Borfecchia, E.; Dyballa, M.; Pankin, I. A.; Lomachenko, K. A.; Martini, A.; Signorile, M.; Teketel, S.; Arstad, B.; Berlier, G.; et al. Methane to Methanol: Structure-Activity Relationships for Cu-CHA. J. Am. Chem. Soc. 2017, 139, 14961-14975.

(8) Kulkarni, A. R.; Zhao, Z.-J.; Siahrostami, S.; Nørskov, J. K.; Studt, F. Monocopper Active Site for Partial Methane Oxidation in $\mathrm{Cu}-$ Exchanged 8MR Zeolites. ACS Catal. 2016, 6, 6531-6536.

(9) Wulfers, M. J.; Teketel, S.; Ipek, B.; Lobo, R. F. Conversion of methane to methanol on copper-containing small-pore zeolites and zeotypes. Chem. Commun. 2015, 51, 4447-4450.

(10) Dinh, K. T.; Sullivan, M. M.; Narsimhan, K.; Serna, P.; Meyer, R. J.; Dincă, M.; Román-Leshkov, Y. Continuous Partial Oxidation of Methane to Methanol Catalyzed by Diffusion-Paired Copper Dimers in
Copper-Exchanged Zeolites. J. Am. Chem. Soc. 2019, 141, 1164111650 .

(11) Koishybay, A.; Shantz, D. F. Water Is the Oxygen Source for Methanol Produced in Partial Oxidation of Methane in a Flow Reactor over Cu-SSZ-13. J. Am. Chem. Soc. 2020, 142, 11962-11966.

(12) Sushkevich, V. L.; Palagin, D.; Ranocchiari, M.; van Bokhoven, J. A. Selective anaerobic oxidation of methane enables direct synthesis of methanol. Science 2017, 356, 523-527.

(13) Palagin, D.; Sushkevich, V. L.; van Bokhoven, J. A. Water Molecules Facilitate Hydrogen Release in Anaerobic Oxidation of Methane to Methanol over $\mathrm{Cu} /$ Mordenite. ACS Catal. 2019, 9, 10365-10374.

(14) Arvidsson, A. A.; Zhdanov, V. P.; Carlsson, P.-A.; Grönbeck, H.; Hellman, A. Metal dimer sites in ZSM-5 zeolite for methane-tomethanol conversion from first-principles kinetic modelling: is the $[\mathrm{Cu}-\mathrm{O}-\mathrm{Cu}]^{2+}$ motif relevant for $\mathrm{Ni}, \mathrm{Co}, \mathrm{Fe}, \mathrm{Ag}$, and $\mathrm{Au}$ ? Catal. Sci. Technol. 2017, 7, 1470-1477.

(15) Borfecchia, E.; Pappas, D. K.; Dyballa, M.; Lomachenko, K. A.; Negri, C.; Signorile, M.; Berlier, G. Evolution of active sites during selective oxidation of methane to methanol over $\mathrm{Cu}-\mathrm{CHA}$ and $\mathrm{Cu}$ MOR zeolites as monitored by operando XAS. Catal. Today 2019, 333, $17-27$.

(16) Hammond, C.; Forde, M. M.; Ab Rahim, M. H.; Thetford, A.; He, Q.; Jenkins, R. L.; Dimitratos, N.; Lopez-Sanchez, J. A.; Dummer, N. F.; Murphy, D. M.; et al. Direct Catalytic Conversion of Methane to Methanol in an Aqueous Medium by using Copper-Promoted Fe-ZSM5. Angew. Chem., Int. Ed. 2012, 51, 5129-5133.

(17) Paolucci, C.; Parekh, A. A.; Khurana, I.; Di Iorio, J. R.; Li, H.; Caballero, J. D. A.; Shih, A. J.; Anggara, T.; Delgass, W. N.; Miller, J. T.; et al. Catalysis in a Cage: Condition-Dependent Speciation and Dynamics of Exchanged Cu Cations in SSZ-13 Zeolites. J. Am. Chem. Soc. 2016, 138, 6028-6048.

(18) Zhao, Z.-J.; Kulkarni, A.; Vilella, L.; Nørskov, J. K.; Studt, F. Theoretical Insights into the Selective Oxidation of Methane to Methanol in Copper-Exchanged Mordenite. ACS Catal. 2016, 6, 37603766.

(19) Ipek, B.; Wulfers, M. J.; Kim, H.; Göltl, F.; Hermans, I.; Smith, J. P.; Booksh, K. S.; Brown, C. M.; Lobo, R. F. Formation of $\left[\mathrm{Cu}_{2} \mathrm{O}_{2}\right]^{2+}$ and $\left[\mathrm{Cu}_{2} \mathrm{O}\right]^{2+}$ toward $\mathrm{C}-\mathrm{H}$ Bond Activation in $\mathrm{Cu}-\mathrm{SSZ}-13$ and $\mathrm{Cu}-$ SSZ-39. ACS Catal. 2017, 7, 4291-4303.

(20) Engedahl, U.; Grönbeck, H.; Hellman, A. First-Principles Study of Oxidation State and Coordination of Cu-Dimers in Cu-SSZ-13 during Methane-to-Methanol Reaction Conditions. J. Phys. Chem. C 2019, 123, 26145-26150.

(21) Shiota, Y.; Yoshizawa, K. Methane-to-Methanol Conversion by First-Row Transition-Metal Oxide Ions: $\mathrm{ScO}^{+}, \mathrm{TiO}^{+}, \mathrm{VO}^{+}, \mathrm{CrO}^{+}$ $\mathrm{MnO}^{+}, \mathrm{FeO}^{+}, \mathrm{CoO}^{+}, \mathrm{NiO}^{+}$, and $\mathrm{CuO}^{+}$. J. Am. Chem. Soc. 2000, 122, 12317-12326.

(22) Vilella, L.; Studt, F. The Stability of Copper Oxo Species in Zeolite Frameworks. Eur. J. Inorg. Chem. 2016, 1514-1520.

(23) Mao, Y.; Hu, P. Identification of the active sites and mechanism for partial methane oxidation to methanol over copper-exchanged CHA zeolites. Sci. China Chem. 2020, 63, 850-859.

(24) Sushkevich, V. L.; Palagin, D.; van Bokhoven, J. A. The Effect of the Active-Site Structure on the Activity of Copper Mordenite in the Aerobic and Anaerobic Conversion of Methane into Methanol. Angew. Chem., Int. Ed. 2018, 57, 8906-8910.

(25) Knorpp, A. J.; Pinar, A. B.; Baerlocher, C.; McCusker, L. B.; Casati, N.; Newton, M. A.; Checchia, S.; Meyet, J.; Palagin, D.; Bokhoven, J. A. Paired Copper Monomers in Zeolite Omega: The Active Site for Methane-to-Methanol Conversion. Angew. Chem., Int. Ed. 2021, 60, 5854-5858.

(26) Heard, C. J.; Grajciar, L.; Nachtigall, P. The effect of water on the validity of Löwenstein's rule. Chem. Sci. 2019, 10, 5705-5711.

(27) Engedahl, U.; Arvidsson, A. A.; Grönbeck, H.; Hellman, A. Reaction Mechanism for Methane-to-Methanol in Cu-SSZ-13: FirstPrinciples Study of the $\mathrm{Z}_{2}[\mathrm{Cu} 2 \mathrm{O}]$ and $\mathrm{Z}_{2}\left[\mathrm{Cu}_{2} \mathrm{OH}\right]$ Motifs. Catalysts 2021, 11, 17. 
(28) Kresse, G.; Hafner, J. Ab Initio molecular dynamics for liquid metals. Phys. Rev. B: Condens. Matter Mater. Phys. 1993, 47, 558-561.

(29) Kresse, G.; Furthmüller, J. Efficiency of Ab-Initio Total Energy Calculations for Metals and Semiconductors Using a Plane-Wave Basis Set. Comput. Mater. Sci. 1996, 6, 15-50.

(30) Kresse, G.; Furthmüller, J. Efficient Iterative Schemes for Ab Initio Total-Energy Calculations Using a Plane-Wave Basis Set. Phys. Rev. B: Condens. Matter Mater. Phys. 1996, 54, 11169-11186.

(31) Kresse, G.; Hafner, J. Norm-conserving and ultrasoft pseudopotentials for first-row and transition elements. J. Phys. Condens. Matter 1994, 6, 8245-8257.

(32) Klimes, J.; R Bowler, D.; Michaelides, A. Chemical accuracy for the Van der Waals density functional. J. Phys.: Condens. Matter 2009, 22, 022201.

(33) Klimes, J.; Bowler, D. R.; Michaelides, A. Van der Waals density functionals applied to solids. Phys. Rev. B: Condens. Matter Mater. Phys. 2011, 83, 195131.

(34) Blöchl, P. E. Projector Augmented-Wave Method. Phys. Rev. B: Condens. Matter Mater. Phys. 1994, 50, 17953-17979.

(35) Kresse, G.; Joubert, D. From ultrasoft pseudopotentials to the projector augmented-wave method. Phys. Rev. B: Condens. Matter Mater. Phys. 1999, 59, 1758-1775.

(36) Dion, M.; Rydberg, H.; Schröder, E.; Langreth, D. C.; Lundqvist, B. I. Van der Waals Density Functional for General Geometries. Phys. Rev. Lett. 2004, 92, 246401.

(37) Lee, K.; Murray, E. D.; Kong, L.; Lundqvist, B. I.; Langreth, D. C. Higher-accuracy van der Waals density functional. Phys. Rev. B: Condens. Matter Mater. Phys. 2010, 82, 081101.

(38) Berland, K.; Hyldgaard, P. Exchange functional that tests the robustness of the plasmon description of the Van der Waals density functional. Phys. Rev. B: Condens. Matter Mater. Phys. 2014, 89, 035412.

(39) Sheppard, D.; Terrell, R.; Henkelman, G. Optimization methods for finding minimum energy paths. J. Chem. Phys. 2008, 128, 134106.

(40) Henkelman, G.; Jónsson, H. Improved tangent estimate in the nudged elastic band method for finding minimum energy paths and saddle points. J. Chem. Phys. 2000, 113, 9978-9985.

(41) Henkelman, G.; Uberuaga, B. P.; Jónsson, H. A climbing image nudged elastic band method for finding saddle points and minimum energy paths. J. Chem. Phys. 2000, 113, 9901-9904.

(42) Hjorth Larsen, A.; Jørgen Mortensen, J.; Blomqvist, J.; Castelli, I. E.; Christensen, R.; Dułak, M.; Friis, J.; Groves, M. N.; Hammer, B.; Hargus, C.; et al. The atomic simulation environment-a Python library for working with atoms. J. Phys.: Condens. Matter 2017, 29, 273002.

(43) Bahn, S. R.; Jacobsen, K. W. An object-oriented scripting interface to a legacy electronic structure code. Comput. Sci. Eng. 2002, 4, $56-66$.

(44) Chorkendorff, I.; Niemantsverdriet, J. W. Concepts of Modern Catalysis and Kinetics; John Wiley \& Sons, 2006.

(45) Tang, W.; Sanville, E.; Henkelman, G. A grid-based Bader analysis algorithm without lattice bias. J. Phys.: Condens. Matter 2009, 21,084204 .

(46) Sanville, E.; Kenny, S. D.; Smith, R.; Henkelman, G. An Improved Grid-Based Algorithm for Bader Charge Allocation. J. Comput. Chem. 2007, 28, 899-908.

(47) Arnaldsson, A.; Jonsson, H. A Fast and Robust Algorithm for Bader Decomposition of Charge Density. Comput. Mater. Sci. 2006, 36, 354-360.

(48) Yu, M.; Trinkle, D. R. Accurate and efficient algorithm for Bader charge integration. J. Chem. Phys. 2011, 134, 064111.

(49) Jørgensen, M.; Chen, L.; Grönbeck, H. Monte Carlo Potential Energy Sampling for Molecular Entropy in Zeolites. J. Phys. Chem. C 2018, 122, 20351-20357.

(50) Chen, L.; Janssens, T. V. W.; Vennestrøm, P. N. R.; Jansson, J.; Skoglundh, M.; Grönbeck, H. A Complete Multisite Reaction Mechanism for Low-Temperature $\mathrm{NH}_{3}$-SCR over $\mathrm{Cu}-\mathrm{CHA}$. ACS Catal. 2020, 10, 5646-5656.
(51) Reuter, K.; Scheffler, M. Composition, structure, and stability of $\mathrm{RuO}_{2}(110)$ as a function of oxygen pressure. Phys. Rev. B: Condens. Matter Mater. Phys. 2001, 65, 1-11.

(52) Arvidsson, A. A.; Plessow, P. N.; Studt, F.; Hellman, A. Influence of Acidity on the Methanol-to-DME Reaction in Zeotypes: A First Principles-Based Microkinetic Study. J. Phys. Chem. C 2020, 124, 14658-14663.

(53) Horvatits, C.; Li, D.; Dupuis, M.; Kyriakidou, E. A.; Walker, E. A. Ethylene and water co-adsorption on $\mathrm{Ag} / \mathrm{SSZ}-13$ zeolites: a theoretical study. J. Phys. Chem. C 2020, 124, 7295-7306.

(54) Virtanen, P.; Gommers, R.; Gommers, R.; Oliphant, T. E.; Haberland, M.; Reddy, T.; Cournapeau, D.; Burovski, E.; Peterson, P.; Weckesser, W.; et al. SciPy 1.0: Fundamental Algorithms for Scientific Computing in Python. Nat. Methods 2020, 17, 261-272.

(55) Hindmarsh, A. C. ODEPACK, A Systematized Collection of ODE Solvers. Sci. Comput. 1983, 55-64.

(56) Moré, J. J.; Garbow, B. S.; Hillstrom, K. E. User guide for MINPACK-1; Argonne National Lab. CM-P00068642, 1980.

(57) NIST Computational Chemistry Comparison and Benchmark Database, NIST Standard Reference Database Number 101; NIST, 1999.

(58) Gurvich, L.; Veyts, I.; Alcock, C. Thermodynamic Properties of Individual Substances, 4th ed.; Hemisphere Pub. Corp., 1989.

(59) Wang, X.; Chen, L.; Vennestrøm, P. N. R.; Janssens, T. V. W.; Jansson, J.; Grönbeck, H.; Skoglundh, M. Direct measurement of enthalpy and entropy changes in $\mathrm{NH}_{3}$ promoted $\mathrm{O}_{2}$ activation over $\mathrm{Cu}$ CHA at low temperature. Chem CatChem 2021, 13, 2577.

(60) Chen, L.; Janssens, T. V. W.; Grönbeck, H. A comparative test of different density functionals for calculations of $\mathrm{NH}_{3}$-SCR over $\mathrm{Cu}$ Chabazite. Phys. Chem. Chem. Phys. 2019, 21, 10923-10930.

(61) Allegra, A. L.; Ambarish, R. K.; Hassan, A.; Joseph, H. M.; Jong Suk, Y.; Charlie, T.; Frank, A.-P.; Felix, S.; Jens, K. N. Understanding trends in $\mathrm{C}-\mathrm{H}$ bond activation in heterogeneous catalysis. Nat. Mater. 2017, 16, 225-229.

(62) Schmieg, S. J.; Oh, S. H.; Kim, C. H.; Brown, D. B.; Lee, J. H.; Peden, C. H. F.; Kim, D. H. Thermal durability of Cu-CHA NH3-SCR catalysts for diesel NOx reduction. Catal. Today 2012, 184, 252-261.

(63) Ipek, B.; Lobo, R. F. Catalytic Conversion of Methane to Methanol on Cu-SSZ-13 Using $\mathrm{N}_{2} \mathrm{O}$ as Oxidant. Chem. Commun. 2016, 52, 13401-13404.

(64) Narsimhan, K. Catalytic, low temperature oxidation of methane into methanol over copper-exchanged zeolites. Ph.D. Thesis, Massachusetts Institute of Technology, 2017. 